\title{
O uso de plantas medicinais por moradores de Quixadá-Ceará
}

OLIVEIRA, D.M.S'; LUCENA, E.M.P. ${ }^{*}$

'Universidade Estadual do Ceará, Curso de Especialização em Ciência de Alimentos, Av. Paranjana, 1.700, Itaperi, CEP 60.740-903, Fortaleza, CE, Brasil *Autor para correspondência: eliseu.lucena@uece.br

\begin{abstract}
RESUMO: O presente trabalho teve por objetivo observar o uso de plantas medicinais por moradores de Quixadá-Ceará. A amostragem adotada foi 5\% da população urbana adulta na sede do município, o que resultou em 263 domicílios visitados, onde foi aplicado um questionário semi-estruturado. De acordo com os resultados ainda temos um número expressivo de pessoas que fazem uso de plantas medicinais na cidade de Quixadá-Ceará $(57,41 \%)$, e que a maioria dos entrevistados (97\%) considera que o uso indiscriminado de plantas medicinais não causa nenhum problema à saúde. A maioria dos entrevistados foram mulheres $(63,57 \%)$ e o maior número de informações e conhecimentos sobre plantas medicinais concentrou-se na faixa de 51-60 anos (24,71\%). Com relação ao nível de escolaridade, 34,22\% dos entrevistados afirmou ter ensino médio completo. A família botânica mais representativa foi a Lamiaceae $(21,05 \%)$ e a espécie mais citada foi a erva-cidreira. Dos entrevistados $93,37 \%$ consideraram utilizar o chá como medicamento e $6,63 \%$ alegaram fazer a utilização do mesmo como alimento. Quanto à frequência do uso de plantas medicinais de forma contínua, $27 \%$ alegaram fazer 0 uso diariamente.
\end{abstract}

Palavras-chave: fitoterápico, fitoterapia, etnobotânica

\begin{abstract}
The use of medicinal plants to habitants from Quixada-Ceara. This study aimed to observe the use of medicinal plants by residents from Quixada-Ceara. The sample used was $5 \%$ of the adult urban population in the county seat, which resulted in 263 households visited, where we applied a semi-structured questionnaire. According to the results, there is still a significant number of people who uses medicinal plants in the city of Quixada-Ceara $(57.41 \%)$, and the majority of participants $(97 \%)$ consider that the indiscriminate employment of medicinal plants do not cause any health problem. Most respondents were female $(63.57 \%)$ and the highest number of information and knowledge about medicinal plants were concentrated among 51-60 years old individuals (24.71\%). In regard of the educational level, $34.22 \%$ of the participants claimed to have completed high school. The botanical family Lamiaceae was the most representative (21.05\%) and the most cited specie was the lemongrass. $93.37 \%$ of the respondents pledged to use tea as medicine and $6.63 \%$ claimed to use it as food. Regarding the employment frequency of the medicinal plants, $27 \%$ claimed to take them daily.
\end{abstract}

Keywords: phytomedicine, phytotherapy, ethnobotany.

\section{INTRODUÇÃO}

O uso de plantas medicinais é a forma de medicina mais antiga na civilização, pois existem registros desde o ano de 2500 a.C. na China. Neste sentido, de acordo com Alves (2013), além da China, existem também observações registradas sobre o uso terapêutico das plantas medicinais desde a antiguidade pelas civilizações indiana, egípcia e grega.

Para que uma planta seja caracterizada como medicinal e possa ser utilizada como fitoterápico, é necessário que ela possua em um ou vários de seus órgãos, substâncias que possam ser empregadas para fins terapêuticos ou sejam precursoras de substâncias utilizadas para tais fins (Amarozo, 2002).

Muitas pessoas que fazem o uso dos fitoterápicos, acham que por serem naturais não fazem mal à saúde. Este é um conceito errôneo, pois existem muitas plantas medicinais dotadas de toxicidade, devido à existência de determinados constituintes farmacologicamente ativos, como os alcaloides, que em doses não terapêuticas podem 
ser letais (Cunha et al., 2003).

Neste sentido, o presente trabalho teve como objetivo avaliar o uso de plantas medicinais por moradores de Quixadá-Ceará, bem como a concepção que têm deste uso.

\section{MATERIAL E MÉTODO}

O município de Quixadá-CE situa-se no bioma Caatinga e era habitado pelos índios tapuias e canindés, que aos poucos, foram abandonando a região, a medida que seus domínios eram conquistados pelos brancos. Está localizado a 168 $\mathrm{Km}$ de Fortaleza-CE, nas coordenadas $4^{\circ} 97^{\prime} \mathrm{S}$ e $39^{\circ} 01^{\prime} \mathrm{W}$, com uma população de 80.604 habitantes, onde $69,63 \%$ de sua população reside na zona urbana e $30,37 \%$ na zona rural (IBGE, 2010).

Foi aplicado questionário semi-estruturado, composto de 15 perguntas relacionadas ao uso de plantas medicinais em visitas às residências de moradores, de acordo com as normas estabelecidas pelo Comitê de Ética em Pesquisa (CEP) da Universidade Estadual do Ceará - UECE (número do processo 04884512.3.0000.5534). O critério utilizado para definir quantas pessoas deveriam ser entrevistadas foi adotar uma amostra de 5\% da população urbana adulta na sede do município, o que resultou em 263 domicílios. Já para definir quais as pessoas que deveriam ser entrevistadas, foi feito de forma aleatória, por meio do sorteio das ruas nos diferentes bairros da cidade de Quixadá-CE (Cebrián \& Garcia, 2000).

As entrevistas foram realizadas entre $07 \mathrm{~h} 00 \mathrm{~min}$ a $11 \mathrm{~h} 00 \mathrm{~min}$ e entre $16 \mathrm{~h} 30 \mathrm{~min}$ a $18 \mathrm{~h} 00 \mathrm{~min}$, em dias úteis e aos sábados nos horários entre $08 \mathrm{~h} 00 \mathrm{~min}$ às $10 \mathrm{~h} 30 \mathrm{~min}$. Durante as entrevistas, as pessoas relataram sobre os seus dados socioeconômicos, qual a frequência no uso de chás, quais as plantas utilizadas, qual a parte utilizada, se utilizava as plantas como alimento e/ ou medicamento, quando era como alimento se saciava a fome e quando era como medicamento quais as doenças eram curadas, qual a forma de aquisição da planta, se havia conhecimento dos riscos toxicológicos das plantas utilizadas, qual a dosagem administrada, proporção no uso de plantas e medicamentos químicos e se sentiam alguma reação alérgica durante o uso das plantas medicinais.

\section{RESULTADO E DISCUSSÃO}

Foram realizadas 263 entrevistas, representando aproximadamente $5 \%$ da população adulta da cidade, destas 151 usam plantas medicinais $(57,41 \%)$ e fizeram 19 citações de espécies diferentes, pertencentes à 16 famílias
(Tabela 1). Dos que usam plantas medicinais, $93,37 \%$ consideraram utilizar o chá como medicamento e $6,63 \%$ alegaram fazer a utilização do mesmo como alimento. Dentre as espécies citadas, 7 são referidas na resolução da Agência Nacional de Vigilância Sanitária (ANVISA), que regulamentou uma lista de várias plantas medicinais de uso tradicional com efeito comprovado cientificamente, além das formas corretas de uso e contra-indicação das mesmas (ANVISA, 2010).

Dentre os 151 entrevistados, 96 foram mulheres $(63,57 \%)$, fato que ocorre devido à maioria das mulheres de regiões interioranas permanecerem em casa cuidando dos afazeres domésticos, conforme destacado por Oliveira \& Menini Neto (2012).

O maior número de informações e conhecimentos sobre as plantas medicinais concentrou-se na faixa etária de 51-60 anos $(24,71 \%)$ (Figura 1$)$, sofrendo um leve decréscimo nas faixas anteriores e elevado nas posteriores. A maior concentração nesta faixa etária se justifica, pois em geral constituem-se de pessoas da população economicamente ativa que possuem principalmente os conhecimentos populares herdados dos antepassados. De acordo com as entrevistas os indivíduos mais jovens pouco se interessam pelo tratamento com plantas medicinais, e, por isso, as desconhecem corroborando com os estudos de Phillips \& Gentry (1993), Amorozo et al. (1996) e Oliveira \& Menini Neto (2012).

Com relação ao nível de escolaridade, $34,22 \%$ dos entrevistados afirmou ter ensino médio completo, seguido por ensino fundamental incompleto $(33,46 \%)$, ensino superior completo $(12,16 \%)$, ensino fundamental completo $(10,26 \%)$, ensino médio incompleto $(6,84 \%)$ e finalmente com ensino superior incompleto (3,04\%). Por outro lado, Schwambach (2007), estudando a utilização de plantas medicinais e medicamentos no autocuidado no município de Teutônia-RS, constatou resultados bastantes diferentes quanto à escolaridade, pois o número de entrevistados com ensino fundamental incompleto foi o mais expressivo (51,5\%), seguido de médio completo $(17,9 \%)$ e finalmente fundamental completo $(13,3 \%)$. Do ponto de vista social, é de conhecimento geral que as camadas de menor renda da população e baixa escolaridade possuem conhecimentos básicos da medicina natural (Lima et al., 2011).

A família botânica mais representativa foi a Lamiaceae, com 118 citações, representando 21,05\% das espécies. É frequente a maior representação desta família em estudos etnobotânicos e/ou etnofarmocológico como pode ser observado, por exemplo, Vendruscolo \& Mentz (2006), Magalhães et al. (2009) e Oliveira \& Menini Neto (2012), pois é

Rev. Bras. PI. Med., Campinas, v.17, n.3, p.407-412, 2015. 
TABELA 1. Espécies de plantas medicinais utilizadas na cidade de Quixadá-CE.

\begin{tabular}{|c|c|c|c|c|}
\hline $\begin{array}{l}\text { Nome } \\
\text { popular }\end{array}$ & Nome científico & $\begin{array}{l}\text { Parte } \\
\text { usada }\end{array}$ & $\begin{array}{l}\text { Forma de } \\
\text { preparo }\end{array}$ & Indicação terapêutica \\
\hline Alfavaca & Ocimum basilicum L. (Lamiaceae) & Folha & Chá & Problema cardiovascular \\
\hline Aroeira & Schinus terebinthifolius Raddi (Anacardiaceae) & Caule & Chá & $\begin{array}{c}\text { Gastrite/inflamação/infecção } \\
\text { urinaria/úlcera }\end{array}$ \\
\hline Boldo & Plectranthus barbatus Andrews (Lamiaceae) & Folha & Chá & Intestino \\
\hline Camomila & Matricaria recutita L. (Asteraceae) & Flor & Chá & Insônia/calmante \\
\hline Canela & Cinnamomum zeylanicum Blume. (Lauraceae) & Caule & Chá & Estômago/resfriados \\
\hline Capim-santo & Cymbopogon citratus (DC) Stapf. (Poaceae) & Folha & Chá & Insônia/enxaqueca \\
\hline Chá-verde & Cammelia sinensis (L). Kutntze (Theaceae) & Folha & Chá & Emagrecimento \\
\hline Colônia & $\begin{array}{c}\text { Alpinia zerumbet (Pers.) B.L. Burtt \& R.M.Sm. } \\
\text { (Zingiberaceae) }\end{array}$ & Folha & Chá & Hipertensão \\
\hline Couve & Brassica oleracea L. (Brassicaceae) & Folha & Chá & AVC/Problemas de visão \\
\hline Erva-cidreira & Lippia alba (Mill) N. E. Br. (Verbenaceae) & Folha & Chá & Insônia/calmante \\
\hline Erva-doce & Pimpinella anisum L. (Apiaceae) & Semente & Chá & Insônia/calmante \\
\hline Erva-mate & Ilex paraguariensis_St. Hill. (Aquifoliaceae) & Folha & Chá & Calmante \\
\hline Eucalipto & Eucalyptus globulus Labill. (Myrtaceae) & Folha & Chá & Resfriado \\
\hline Hortelã & Mentha sp. (Lamiaceae) & Folha & Chá & Dor/enxaqueca \\
\hline Jatobá & Hymenaea courbaril L. (Caesalpiniaceae) & Folha & Chá & Úlcera \\
\hline Laranjeira & Citrus sinensis (L.) Osbeck. (Rutaceae) & Fruto & Chá & Náusea \\
\hline Linhaça & Linum usitatissimum L. (Linaceae) & Semente & Chá & $\begin{array}{c}\text { Problema cardíaco/câncer/ } \\
\text { vascular }\end{array}$ \\
\hline Malvarisco & Plectranthus amboinicus (Lour.) Spreng. (Lamiaceae) & Folha & Chá & Inflamação \\
\hline Quebra-pedra & Phylantus niruri L. (Phyllanthaceae) & Raiz & Chá & Pedra nos rins \\
\hline
\end{tabular}

As plantas listadas na resolução da ANVISA (2010) têm seus nomes destacados em negrito.

uma família cosmopolita com muitas espécies que se adaptam bem, tanto em ambientes tropicais quanto aos temperados, e que possuem óleos essenciais variados, justificando esta representatividade.

A espécie mais citada pelos entrevistados foi a erva-cidreira (Lippia alba (Mill) N. E. Br., Verbenaceae) com 113 citações, seguida por hortelã (Mentha sp., Lamiaceae) com 90 citações, capimsanto (Cymbopogon citratus (DC) Stapf., Poaceae) citado 48 vezes, erva-doce (Pimpinella anisum L., Apiaceae) com 25 citações, camomila (Matricaria recutita L., Asteraceae) citada 23 vezes, boldo (Plectranthus barbatus Andrews, Lamiaceae) com 20 citações, eucalipto (Eucalyptus globulus Labill., Myrtaceae) citado 11 vezes, alfavaca (Ocimum basilicum L., Lamiaceae), quebra-pedra (Phylantus niruri L., Phyllanthaceae) e laranjeira (Citrus sinensis (L.) Osbeck., Rutaceae) com 6 citações cada. Muitas destas espécies são citadas comumente em estudos dessa natureza, mas nem sempre nessa ordem de magnitude, como foi destacado nos estudos de Silva et al. (2005) e Lima et al. (2011).

As partes das plantas utilizadas pelos entrevistados foram principalmente as folhas, representando $89,4 \%$ das citações, seguidas de caules, flores, sementes, frutos e raízes. Isso pode ser devido as folhas serem encontradas praticamente em qualquer período do ano e também são facilmente coletadas, corroborando com os estudos de Castellucci et al. (2000), Pereira et al. (2004), Vendruscolo \& Mentz (2005), Silva, Dreveck \& Zeni (2009) e Oliveira \& Menini Neto (2012). Desta forma, o uso das folhas como medicamento é uma forma sustentável de aproveitamento do recurso natural, pois há uma conservação da planta para usos posteriores, não interferindo no seu crescimento e na sua reprodução, conforme destacado por Silva et al. (2009). Por outro lado, quando explora-se o caule ou a raiz como medicamento, pode provocar a morte da planta.

A forma de preparo correto das plantas medicinais deve ser levado em consideração devido aos diferentes óleos essenciais voláteis presentes nas folhas e outros órgãos da planta, segundo Almassy Júnior et al. (2005). O Eugenol, presente na alfavaca, é o composto responsável pelas ações biológicas (Matos, 2000). A forma de preparo mais utilizada pela população de Quixadá é o chá, corroborando com os estudos de Corrêa Júnior et al. (1994), Kffruri (2008) e Oliveira \& Menini Neto (2012).

Com relação ao uso dos chás, diante da pesquisa ficou claro que a maioria das pessoas afirmou que faz o uso desses chás casualmente, mas um bom número informou que faz o uso semanal e diário (27\%). Sabe-se que as partes 


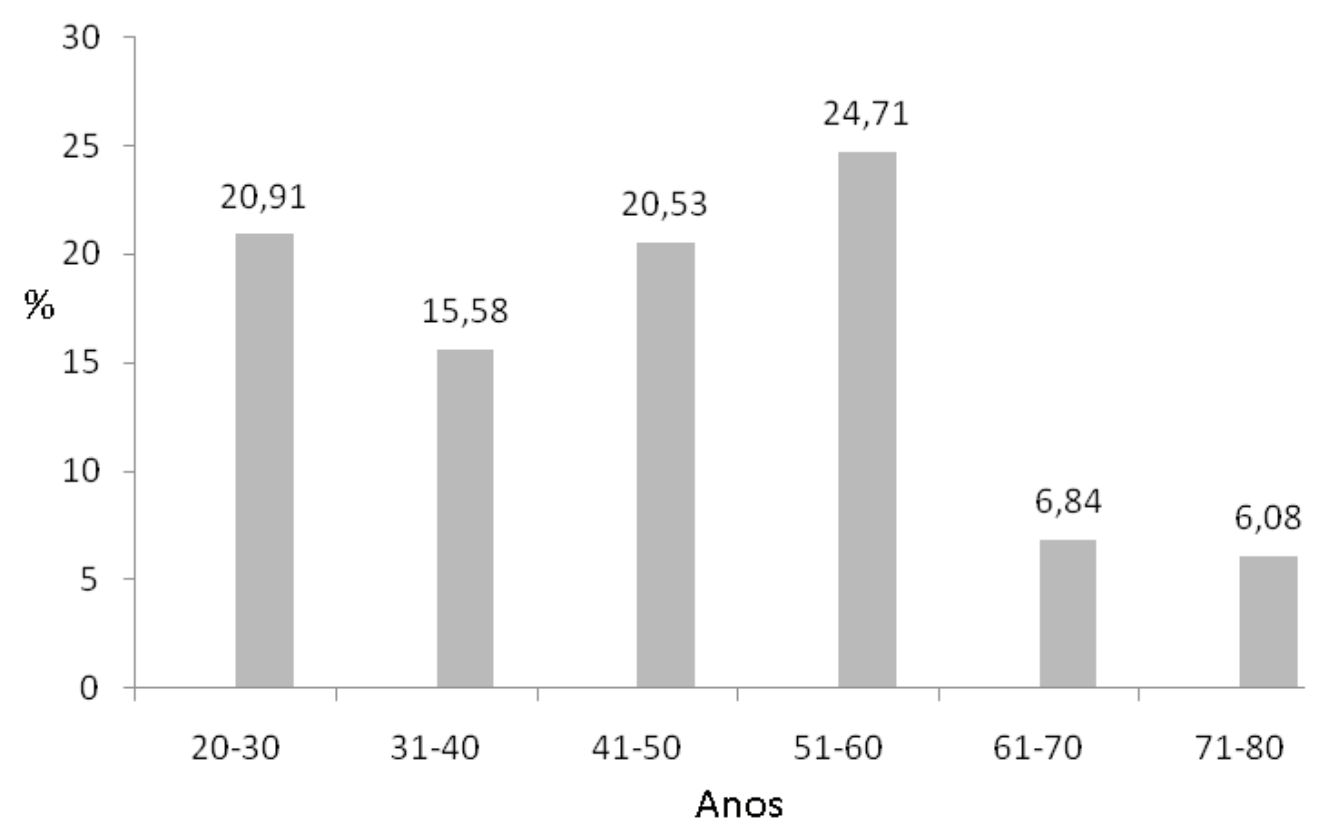

FIGURA 1. Faixa etária dos entrevistados.

vegetais utilizadas para a produção de chás possuem inúmeros compostos químicos associados como, por exemplo, alcaloides, glicídios, cúmarinas, flavonoides, iridóides e naftoquinónicos e estes quando usado de forma indiscriminada e continua, podem vir a causar um processo tóxico no organismo do individuo que está fazendo o seu uso (Cunha et al., 2003).

Devido a quantidade de pessoas $(50,99 \%)$ que ainda cultivam as plantas medicinais em sua própria casa, fica claro que por morarem em casas, em sua grande maioria, ainda tem a disponibilidade para plantar e cultivar as plantas medicinais que utilizam constantemente. Nos resultados encontrados por Silva \& Souza (2007), o número de pessoas que cultivam a planta medicinal no seu próprio quintal foi superior (85\%). Percebe-se que esse é um dos motivos que os fazem utilizarem as plantas medicinais em forma de chá, por um período continuo e prolongado.

Quando indagados quanto a quem lhes ensinou a preparar o chá, se havia ensinado a dosagem, $90 \%$ das pessoas afirmaram que sim e $10 \%$ que não. No tocante a forma de preparo, $80 \%$ das pessoas afirmaram fazem o cozimento das partes das plantas utilizadas, 15\% afirmaram realizar o preparo do chá na forma de infusão e 5\% de outras formas não especificadas.

De acordo com o levantamento etnobotânico de Lima et al. (2011), constataram 9 formas de preparo dos fitoterápicos, sendo o chá, com a fervura da água e das folhas das plantas a forma mais utilizada $(66 \%)$.

A forma correta de preparo de chás é através de infusão, no entanto, a maioria dos entrevistados
(80\%) alegaram cozinhar as partes para a produção de chá, o que não é o correto, por esse motivo, muitos dos óleos essenciais tenham perdido a sua função. Esse também pode ser o motivo pelo qual os riscos de toxidade diminuam. Segundo Martins et al. (1994) as partes mais toxicas dos vegetais são as folhas, portanto, são justamente nelas que encontramos os maiores riscos de toxidade.

Com relação ao uso associado de medicamentos químicos e naturais, 12,9\% usam os dois ao mesmo tempo, mostrando-nos que a maioria não fazem esse uso em concomitância, por temerem que essa associação cause algum dano ao organismo, confirmando os dados obtidos por Menon-Miyake et al. (2004) e Oliveira \& Menini Neto (2012).

Quanto à dosagem a ser tomada, $82 \%$ afirmaram tomar de 1 a 2 xícaras ao dia, $10 \%$ de 2 a 3 xícaras ao dia e $8 \%$ alegaram tomar a quantidade que achar necessário, podendo ultrapassar 4 xícaras ao dia. Isso nos mostra que ocorre uma variação com relação a dosagem de acordo com a experiência do entrevistado, como também observado por Calábria et al. (2008) e Oliveira \& Menini Neto (2012).

Chama a atenção o fato de $97 \%$ dos entrevistados desconhecerem os riscos de toxidade que o uso continuo de algumas plantas medicinais, que foram citadas na entrevista, como o boldo, no entanto, já existem estudos que comprovam que o uso continuo deste, pode vir a causar problemas auditivos severos, como apresentado por Matos (2000). Isso mostra que a falta de informação e esclarecimento leva muitas vezes os indivíduos a fazerem o uso prolongado 
de determinadas plantas sem medo de causar nenhum dano à saúde por ser natural.

As doenças mais tratadas com as plantas medicinais pelos entrevistados foram: insônia, dores, inflamações, ansiedade e problemas estomacais. Resultados semelhantes foram encontrados por Silva-Almeida \& Amorozo (1998), Hanazaki et al. (1996), Amorozo \& Gely (1988) e Oliveira \& Menini Neto (2012).

É possível que esta falta de padronização ou até mesmo o desconhecimento do uso correto dessas plantas, como a correta dosagem, forma de preparo correto e até mesmo a eficiência correta para determinada doença, reduza a eficiência e até mesmo podendo ocasionar reações adversas, advindas desse uso incorreto.

\section{CONCLUSÃO}

Os resultados obtidos permitiram concluir que: o uso de plantas medicinais por moradores de Quixadá-Ceará é muito frequente; os maiores usuários de chás são mulheres; os chás são usados com maior frequência para cura ou prevenção de doenças; e a falta de esclarecimento leva as pessoas a fazerem usos indevidos em relação ao preparo, dosagem e uso continuo de chás.

\section{REFERÊNCIA}

AGÊNCIA NACIONAL DE VIGILÂNCIA SANITÁRIA (ANVISA). Resolução n 10, de 9 de março de 2010. Dispõe sobre notificação de drogas vegetais. Diário Oficial da Republica Federativa do Brasil, Brasília, n.46, p.52, 10 de março de 2010. Seção 1. Disponível em: <http://www.anvisa.gov.br>. Acesso em: 01 set. 2012.

ALMASSY JÚNIOR, A.A. et al. Folhas de chá: plantas medicinais na terapêutica humana. Viçosa: Editora da Universidade Federal de Viçosa, 2005. 233p.

ALVES, L.F. Produção de fitoterápicos no Brasil: história, problemas e perspectivas. Revista Virtual de Química, v.5, n.3, p.450-513, 2013.

AMOROZO, M. C. M. Uso e diversidade de plantas medicinais em Santo Antonio do Leverger, MT, Brasil. Acta Botanica Brasilica, v.16, n.2, p.189-203, 2002.

AMOROZO, M.C.M.; GELY, A.L. Uso de plantas medicinais por caboclos do baixo Amazonas, Barcarena, PA, Brasil. Boletim do Museu Paraense Emílio Goeldi, Série Botânica, v.4, n.1, p.47-131,1988.

AMOROZO, M.C.M.; REIS, M.S.; FERRI, P.H. Aabordagem etnobotânica na pesquisa de plantas medicinais. In: DI STASI, L.C. (Org.). Plantas medicinais: arte e ciência - um guia de estudo interdisciplinar. São Paulo: Editora da Universidade Estadual Paulista, 1996. p.47-68.

CALÁBRIA, L. et al. Levantamento etnobotânico e etnofarmocológico de plantas medicinais em Indianópolis, Minas Gerais, Brasil. Revista Brasileira de
Plantas Medicinais, v.10, n.1, p.49-63, 2008.

CASTELLUCCI, S. et al. Plantas medicinais relatadas pela comunidade residente na Estação Ecológica de Jataí, município de Luís Antonio/SP: uma abordagem etnobotânica. Revista Brasileira de Plantas Medicinais, v.3, n.1, p.51-60, 2000.

CEBRIÁN, A.A.; GARCIA, M.M.R. Tamaño y selección de muestras en poblaciones finitas. Pharmaceutical Care, v.2, p.310-320, 2000.

CORRÊA JÚNIOR, C.; MING, L.C., SCHEFFER, M.C. Cultivo de plantas medicinais, aromáticas e condimentares. Jaboticabal: FUNEP, 1994, 162p.

CUNHA, A.P.; SILVA, A.P.; ROQUE, O.R. Plantas e produtos vegetais em fitoterapia. 1.ed. Lisboa: Fundação Calouste Gulbenkian, 2003. 303p.

HANAZAKI, N.; LEITÃO FILHO, H.F.; BEGOSSI, A. Uso de recursos na Mata Atlântica: o caso da Ponta do Almada. Intersciência, v.21, n.6, p.268-276, 1996.

INSTITUTO BRASILEIRO DE GEOGRAFIA E ESTATÍSTICA (IBGE). Censo Demográfico 2010. Disponível em: <http://www.ibge.gov.br/cidadesat/ painel/painel. php?codmun=231130\#>. Acesso em: 10 set. 2012.

KFFURI, C.W. Etnobotânica de plantas medicinais no município de Senador Firmino, Minas Gerais. 2008. 88p. Dissertação (Mestrado em Fitotecnia) - Universidade Federal de Viçosa, Viçosa.

LIMA, A.R.; MAGALHÃES, A.S.; SANTOS, A.R.M.; Levantamento etnobotanico de plantas medicinais utilizadas na cidade de Vilhena, Rondônia. Revista pesquisa \& Criação, v.10, n.2, p.165-179, 2011.

MAGALHÃES, V.C. et al. Levantamento etnobotânico na comunidade rural Sapucaia em Santo Antônio de Jesus, Recôncavo da Bahia - BA. Revista Brasileira de Agroecologia, v.4, n.2, p.2071-2074, 2009.

MARTINS, E.R. et al. Plantas medicinais. Viçosa: Editora da Universidade Federal de viçosa, 1994, 220p.

MATOS, F.J.A. Plantas medicinais: guia de seleção e emprego de plantas usadas em fitoterapia no nordeste do Brasil. 2.ed. Fortaleza: Imprensa Universitária da Universidade Federal do Ceará, 2000. 144 p

MENON-MIYAKE, M.A. et al. Inquérito sobre o uso de plantas medicinais para tratamento de afecções otorrinolaringológicas entre pacientes de um hospital público terciário. Revista Brasileira de Otorrinolaringologia, v.70, n.2, p.43-55,.2004.

OLIVEIRA, E.R.; MENINI NETO, L. Levantamento etnobotânico de plantas medicinais utilizadas pelos moradores do povoado de Manejo, Lima Duarte - MG. Revista Brasileira de Plantas Medicinais, v.14, n.2 p.311-320, 2012.

PEREIRA, R.C.; OLIVEIRA, M.T.R.; LEMOS, G.C.S. Plantas utilizadas como medicinais no município de campos de Goytacazes-RJ. Revista Brasileira de Farmacognosia, v.14, n.1, p.37-40, 2004.

PHILLIPS, O.; GENTRY, A.H. The useful plants of Tambopata, Peru II: Aditional hypothesis testing in quantitative ethnobotany. Economic Botany, n.47, v.1, p.33-43, 1993.

SCHWAMBACH K.H. Utilização de plantas medicinais e medicamentos no autocuidado no município de Teutônia, RS. 2007. 98p. Dissertação (Mestrado em 
Ciências Farmacêuticas) - Universidade Federal do Rio Grande do Sul, Porto Alegre.

SILVA, F.S. et al. Levantamento etnobotânico das plantas medicinais da zona rural do município de Piumhi, Minas Gerais. Revista Científica Eletrônica de Engenharia Florestal, v.3, n.6. p.1-4, 2005. Disponível em: <http://www.revista.inf.br/florestal06/ pages/artigos/artigo03.pdf $>$. Acesso em : 05 set. 2012.

SILVA, J.O.; SOUZA, P.S. Levantamento etnobotânico das plantas medicinais utilizadas pela população da Vila Canaã região sudoeste - Goiânia, Goiás. 2007. 22p. Monografia (Graduação em Ciências Biológicas) - Uni-Anhanguera, Centro Universitário de Goiás, Goiânia.

SILVA, M.D.; DREVECK, S.; ZENI, A.L.B. Estudo etnobotânico de plantas medicinais utilizadas pela população rural no entorno do Parque Nacional da Serra do Itajaí - Indaial. Revista Saúde e Ambiente, v.10, n.2, p.54-64, 2009.

SILVA-ALMEIDA, M.F.; AMOROZO, M.C.M. Medicina popular no Distrito de Ferraz, Município de Rio Claro, SP. Brazilian Journal of Ecology, v.2, n.1, p.36-46, 1998.

VENDRUSCOLO, G.S.; MENTZ, L.A. Dados químicos e farmacológicos sobre as plantas utilizadas como medicinais pela comunidade do bairro Ponta Grossa, Porto Alegre. Revista Brasileira de Farmacognosia, v.15, p.361-372, 2005.

VENDRUSCOLO, G.S.; MENTZ, L.A. Levantamento etnobotânico das plantas utilizadas como medicinais por moradores do bairro de Ponta Grossa, Porto Alegre, Rio Grande do Sul, Brasil. Iheringia, Série Botânica, v.61, n.1/2, p.83-103, 2006. 